\title{
Amniotic membrane transplantation for severe neurotrophic corneal ulcers
}

\author{
Hong-Jeng Chen, Renato T F Pires, Scheffer C G Tseng
}

\begin{abstract}
Aims-To evaluate whether amniotic membrane transplantation can be an effective alternative treatment for neurotrophic corneal ulcers.

Methods-Amniotic membrane transplantation was performed in 16 eyes of 15 patients with neurotrophic corneal ulcers and vision equal to or worse than 20/200. The neurotrophic state was developed following keratoplasty (four eyes), herpes zoster ophthalmicus (four eyes), diabetes mellitus (four eyes), radiation (two eyes), removal of acoustic neuroma with neuroparalysis (one eye), and herpes simplex keratitis (one eye).

Results-During a mean follow up period of 18.8 (SD 13.0) months, one to three layers of amniotic membrane with or without additional membrane as a patch were used for 17 procedures in 16 eyes for persistent neurotrophic corneal ulcers. All but four (76.4\%) instances of amniotic membrane transplantation achieved rapid epithelialisation in 16.6 (9.0) days. Of the four eyes showing delayed healing, three eyes healed by tarsorrhaphy, and the remaining one eye with corneal perforation required penetrating keratoplasty and tarsorrhaphy. Two eyes gained vision better than 20/200. The healed corneal surface was accompanied by reduced inflammation.

Conclusion-Amniotic membrane transplantation can be considered an effective alternative for treating severe neurotrophic corneal ulcers.

(Br f Ophthalmol 2000;84:826-833)
\end{abstract}

Tear Center,

Department of

Ophthalmology,

Bascom Palmer Eye

Institute, Miami,

Florida, USA

H-J Chen

R T F Pires

S C G Tseng

Department of Cell Biology and Anatomy, University of Miami School of Medicine, Miami, Florida, USA S C G Tseng

Correspondence to: Dr Scheffer C G Tseng, Bascom Palmer Eye Institute, William L

McKnight Vision Research Center, 1638 NW 10th Avenue Miami, FL 33136 USA

stseng@bpei.med.miami.edu

Accepted for publication 23 March 2000 corneal anaesthesia and epithelial breakdowns leading to persistent and progressive neurotrophic ulcers. ${ }^{2}$ Common causes of neuro- trophic keratopathy include herpetic infection (simplex or zoster), alkali burn, diabetes mellitus, tumours affecting the trigeminal ganglion or sensory routes, radiation, and anterior segment surgeries. ${ }^{2-6}$

Current medical treatments include topical artificial tears, lubricants, and experimental trials of fibronectin, ${ }^{78}$ insulin-like growth factor type I and substance $\mathrm{P},{ }^{9}$ or nerve growth factor. ${ }^{10}$ When these medical therapies fail, one may consider patching, scleral contact lens, ${ }^{3}$ cyanoacrylate glue, ${ }^{11}$ conjunctival flap, ${ }^{12}$ and tarsorrhaphy (also reviewed by Donzis and Mondino ${ }^{2}$ ). Recently, amniotic membrane transplantation (AMT) has been successfully used to treat persistent corneal epithelial defects and ulcers from different causes, ${ }^{13-15}$ and for corneal $^{16-23}$ and conjunctival ${ }^{1424-29}$ surface reconstruction for a variety of ocular surface disorders (for review see Pires et $a l^{30}$ ). Here we summarise our experience in using AMT for persistent and progressive neurotrophic corneal ulcers.

\section{Patients and methods}

PATIENTS

This study includes four patients who had been recruited initially for a study approved by the medical science subcommittee for the protection of human subjects in research of the University of Miami School of Medicine, and reported in an earlier publication. ${ }^{13}$ There were a total of 15 patients (16 eyes): 11 males and four females, with ages between 4 and 86 (mean 62.6 (SD 22.2)) years old. AMT had been consecutively performed for a neurotrophic ulcer caused by one or several of the following diseases: post-keratoplasty (nine eyes), herpes zoster ophthalmicus (four eyes), diabetes mellitus (six eyes), radiation for ocular malignant lymphoma and retinoblastoma (two eyes), removal of acoustic neuroma (one eye), and herpes simplex keratitis (one eye). The neurotrophic state of each patient is established by the absence of corneal sensation using a Charcot-Bonnet aesthiometer. Other demographic details are listed in Table 1. Most eyes had received multiple ocular surgeries (see Table 1 for details). These procedures could have contributed to the development of the neurotrophic state. There had been other preexisting ocular diseases that had threatened the visual potential. These included glaucomatous optic nerve atrophy in four eyes, proliferative diabetic retinopathy in one eye, and proliferative vitreoretinopathy from rhegmatogenous retinal detachment in one eye. Owing to these problems, all eyes had a visual acuity equal to or worse than $20 / 200$. 


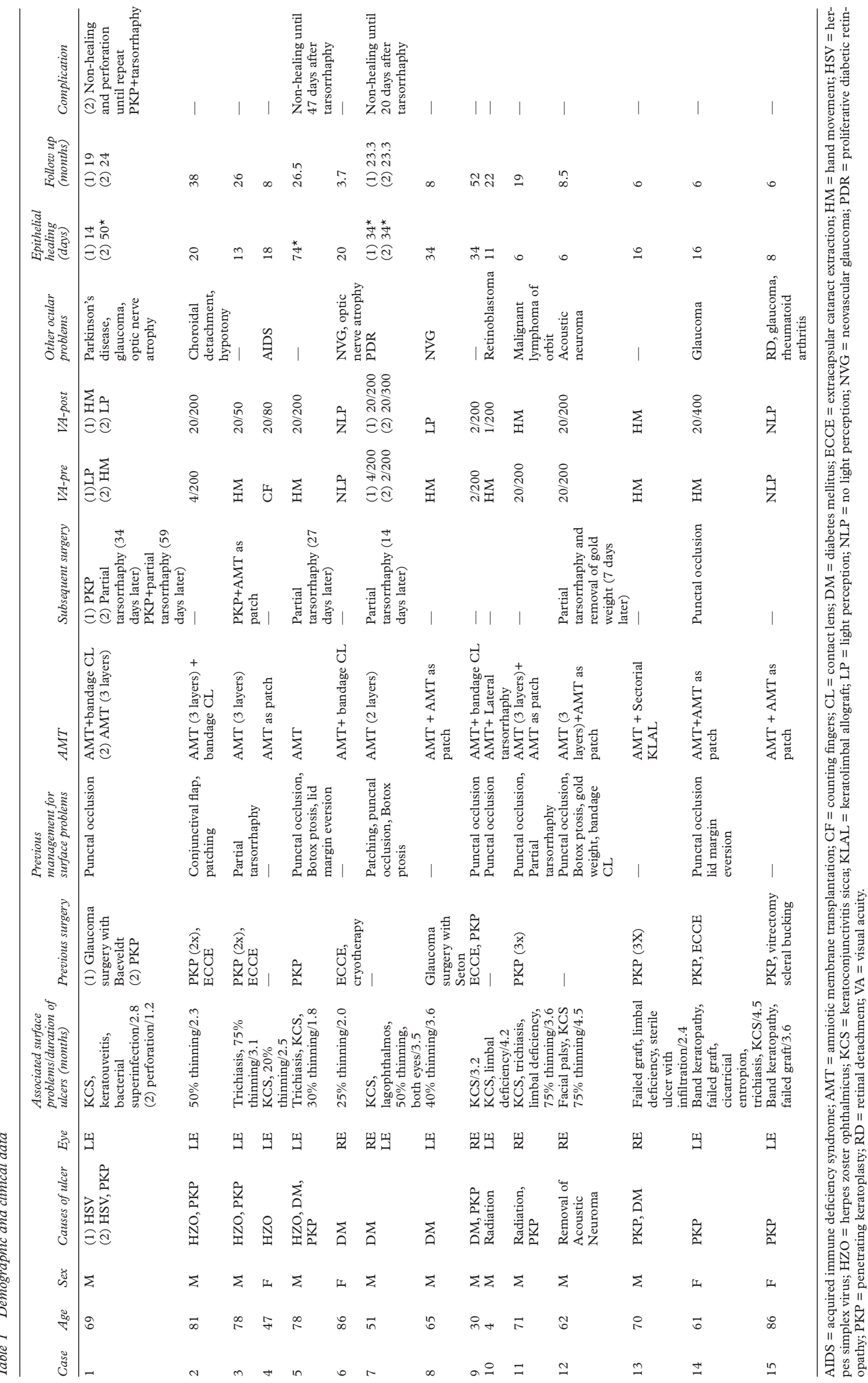


PREPARATION OF PRESERVED HUMAN AMNIOTIC MEMBRANE

In this study, all except for four patients from a previously approved study used amniotic membranes obtained from Bio-Tissue (South Miami, FL, USA), where procurement includes screening against HIV types 1 and 2, human $\mathrm{T}$ lymphoma virus type 1 , hepatitis $\mathrm{B}$ and $\mathrm{C}$ viruses, and syphilis at the time of caesarean delivery and 6 months post partum, and the methods of preparation follow our previous methods. ${ }^{132125}$

\section{AMNIOTIC MEMBRANE TRANSPLANTATION}

All surgical procedures were performed by the same surgeon (SCGT). Except for case 1, in whom AMT was performed twice in the same eye, all others received AMT once in the eye with ulcers. After retrobulbar anaesthetic injection in eyes with neurotrophic ulcer, the base of the ulcer was debrided with a microsponge and fine forceps, and the poorly adherent epithelium adjacent to the edge of the ulcer was removed up to the area where the epithelium became adherent. The amniotic membrane was then removed from the storage medium, peeled from the nitrocellulose filter paper, transferred to the recipient eye, and fitted to fill up the ulcer and cover the defect by trimming off the excess edges. This fashioned membrane with stroma-side down was then secured to the edge of the defect by interrupted 10-0 nylon sutures and, in some cases, by a running 10-0 nylon suture. After the knots had been buried, the corneal surface became smooth as a result of the well approximated amniotic membrane filling in the ulcer bed. More than one layer of amniotic membrane was used if the ulcer was deep, and in those instances (see Table 1) the bottom layers were left unsutured and only the top layer was sutured as described above. Depending on the aqueous tear status and the eyelid blinking function, a bandage contact lens, amniotic membrane as a temporary patch, or temporary tarsorrhaphy was added. When amniotic membrane was used as a patch, this was performed by placing an amniotic membrane over the cornea or extending it beyond the limbus with the basement membrane side facing down, and was sutured either with interrupted 10-0 nylon sutures (if on the cornea) or with a pursestring running 10-0 Vicryl or nylon suture over the perilimbal sclera. This was followed by topical application of Maxitrol ointment (neomycin sulphate, polymyxin $\mathrm{B}$ sulphate, and dexamethasone) (Alcon, Forth Worth, TX, USA).

POSTOPERATIVE CARE AND EVALUATION

Before epithelialisation the patient was followed weekly and was routinely treated with topical Pred Fort (1\% prednisolone acetate) (Allergan, Hormigueros, Puerto Rico), three times a day and Ocuflox (0.3\% ofloxacin) (Allergan, Hormigueros, Puerto Rico) twice a day. After epithelialisation was completed, the latter was discontinued but the former was tapered off. Fluorescein staining was used to detect epithelial defects and documentary photographs were taken if necessary. Following healing, topical antibiotics were discontinued and the topical steroid was tapered off.

\section{STATISTICAL ANALYSIS}

The preoperative and postoperative data were analysed by an unpaired $t$ test based on SPSS version 7.5 (SPSS Inc, Chicago, IL, USA) with the assistance of the department of biostatistics of the Bascom Palmer Eye Institute. A p value of less than 0.05 was considered significant.

\section{Results}

BEFORE AMNIOTIC MEMBRANE TRANSPLANTATION Most eyes had received multiple ocular surgeries. Eleven eyes (68.7\%) received more than two intraocular surgeries (see Table 1 for more details). The main purpose of these procedures was tectonic to restore the anatomic integrity in five eyes $(31.2 \%)$. Nine eyes $(56.2 \%)$ had received penetrating keratoplasty for corneal scarring or ulceration due to previous neurotrophic keratitis. A high frequency of graft failure $(6 / 9,66.6 \%)$ was noted. In addition, other pre-existing ocular diseases such as glaucoma, proliferative diabetic retinopathy, proliferative vitreoretinopathy, and rhegmatogeous retinal detachment had threatened the visual potential. Owing to these problems, all eyes had a visual acuity equal to or worse than $20 / 200$.

These procedures could have contributed to the development of the neurotrophic state. In this series, the neurotrophic state of these 16 eyes was established by the lack of corneal sensation using a Charcot-Bonnet aesthiometer. As a result, there was markedly reduced and infrequent blinking resulting in exposure keratopathy, and varying degrees of aqueous tear deficiency leading to keratoconjunctivitis sicca (see Table 1). For exposure problems, patching and bandage contact lens had been tried in three eyes, ptosis had been induced by botulinum toxin injection in three eyes or implantation of a gold weight to the upper lid in one eye, partial tarsorrhaphy had been performed in two eyes, and conjunctival flap in one eye. For aqueous tear deficiency, punctal occlusion had been performed in eight $(50 \%)$ eyes. Despite the above measures and use of frequent tear substitutes and lubricants and prophylactic antibiotics with or without steroids, all 16 eyes presented with persistent or progressive epithelial defects and stromal ulceration of varying degrees (Table 1) with descemetocele in one eye (case 12) and corneal perforation in one eye (case 1). Their neurotrophic state was further substantiated by a disproportionate lack of subjective symptoms of surface irritation. The principal complaint was reduced vision in all patients and other complaints included annoying redness and ill defined irritation in some cases.

Besides the neurotrophic state, three eyes $(18.7 \%)$ had suffered from mechanical microtrauma caused by additional lid problems such as trichiasis or entropion with misdirected eyelash, and one eye had had additional lagophthalmos. Other ocular abnormalities included 

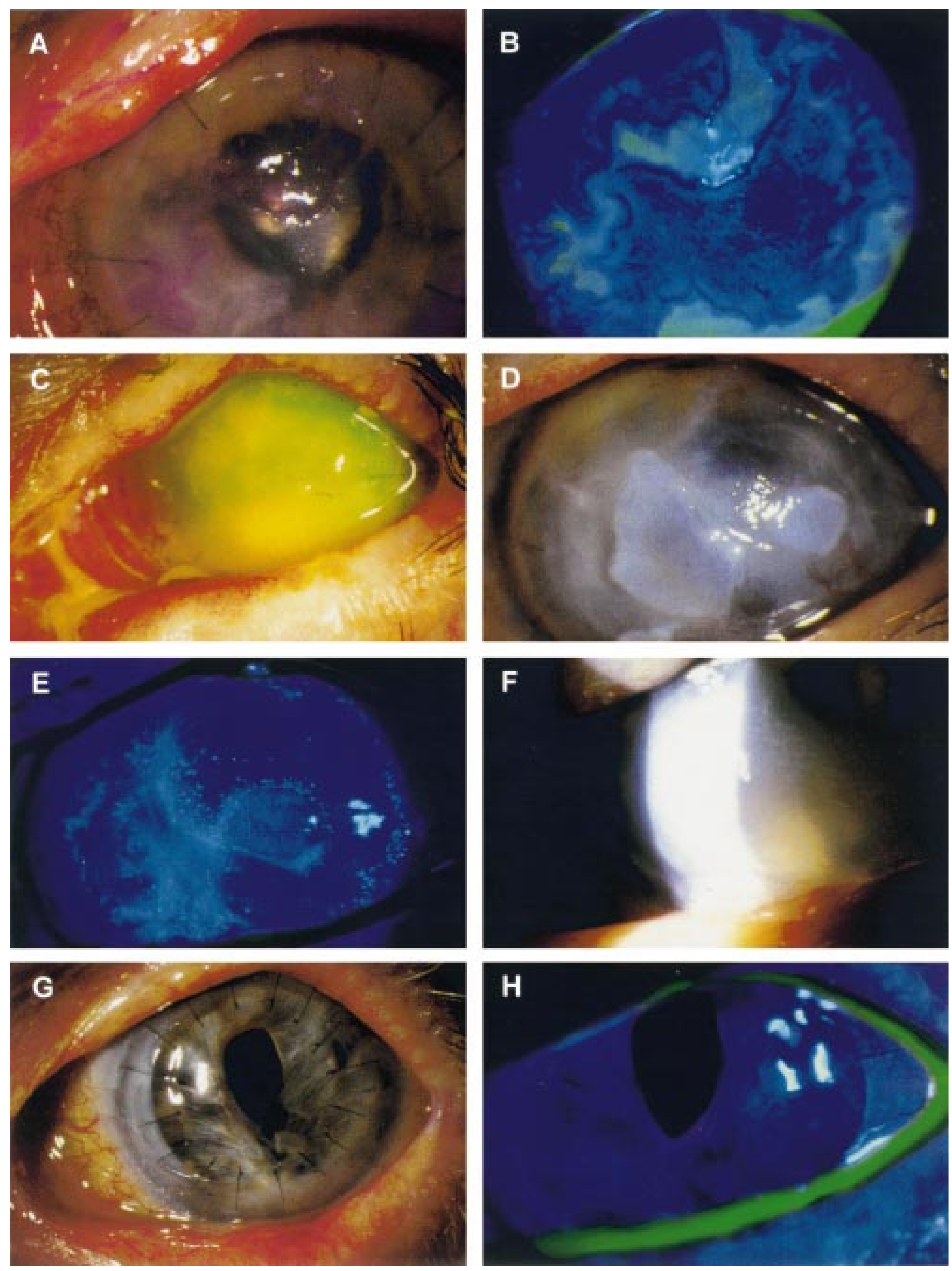

Figure 1 Case 3 had previously undergone a penetrating keratoplasty with tarsorrhaphy for a progressive ulcer and descemetocele caused by herpes zoster ophthalmicus on the left eye. He developed a recurrent herpes zoster with epithelial dendrites and ulcers stained with rose bengal (A) and fluorescein (B), and progressed into disciform and necrotising stromal keratitis. This was complicated by bacterial keratitis, and a large inferior one third hypopyon (C). Following appropriate antibiotics and aciclovir, the sterilised ulcer became thin in several locations of the cornea. Amniotic membrane transplantation was performed and resulted in total healing of the ulcer with a quiet ocular surface in 13 days (D and E). After the corneal surface had been stable for 15 months (F), a repeat PKP was performed and covered with an amniotic membrane as a patch, which was dissolved in 2 weeks, and the graft showed a smooth surface and clear stroma 8 months later $(G$ and $H)$. 

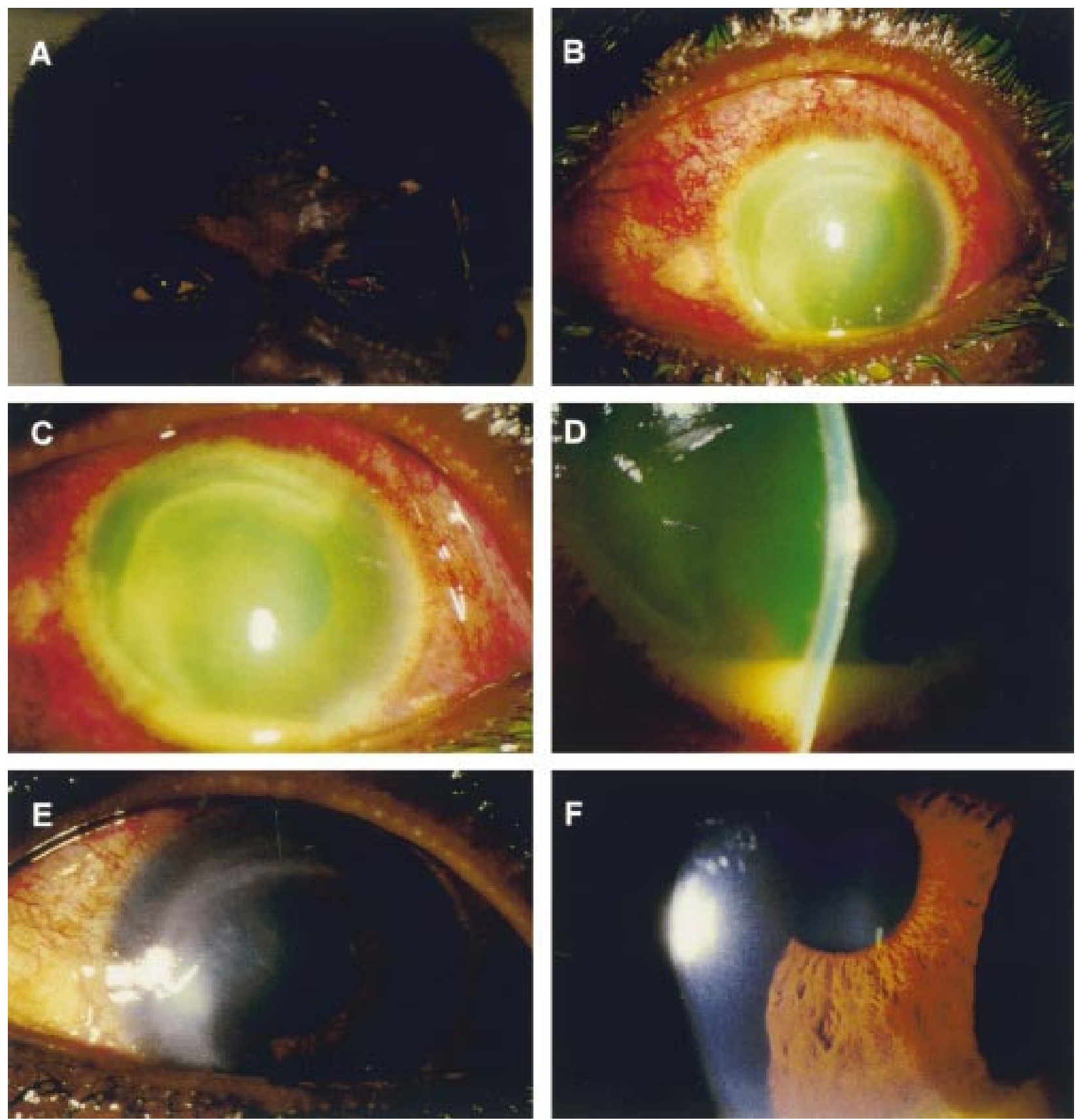

Figure 2 Case 4 had AIDS, had discontinued anti-HIV medications for 1 month, and developed acute herpes zoster ophthalmicus on the left eye (A) with diffuse conjunctival redness and corneal involvement (B). The cornea showed a peripheral circumlinear ulcer with infiltrate, diffuse oedema with keratic precipitates and hypopyon $(C$ and D). Ten days after amniotic membrane transplantation the membrane dissolved, the corneal and conjunctival surfaces were no longer inflamed, and the ulcer healed with resolution of oedema, keratic precipitates, and hypopyon (E and $F$ ).

refractory glaucoma in five eyes and partial limbal stem cell deficiency in three eyes. Systemically, six patients had diabetes mellitus, three patients had hypertension, one patient had AIDS, and one patient had Parkinson's disease.

The neurotrophic ulcer was located in the central cornea in 14 eyes, in the nasal corneal periphery in one eye and at the corneal graft host junction in one eye. According to the respective histories, all these ulcers had been persistent for more than 2 months, and 10 eyes had shown progressive thinning of the ulcer bed. Five eyes $(31.2 \%)$ developed hypopyon. All corneas had significant stromal oedema and inflamed limbus and conjunctiva.
AFTER AMNIOTIC MEMBRANE TRANSPLANTATION Depending on the depth of stromal ulceration, the ulcer was covered by one or more than one layer of amniotic membrane, and the basement membrane side of the last layer was congruent with the patient's exposed surface. These denuded surfaces healed rapidly after AMT. Except for four eyes, all others $(13 / 17,76.4 \%)$ healed within 16.6 (SD 9.0) days. In the two eyes of case 7 with severe diabetes mellitus, the ulcers were not healed on day 14 and partial tarsorrhaphy was added, and the healing was completed on day 34. In the one eye of case 5 with herpes zoster ophthalmicus (HZO) and diabetes mellitus and status post-penetrating keratoplasty, the ulcer did not heal on day 27 

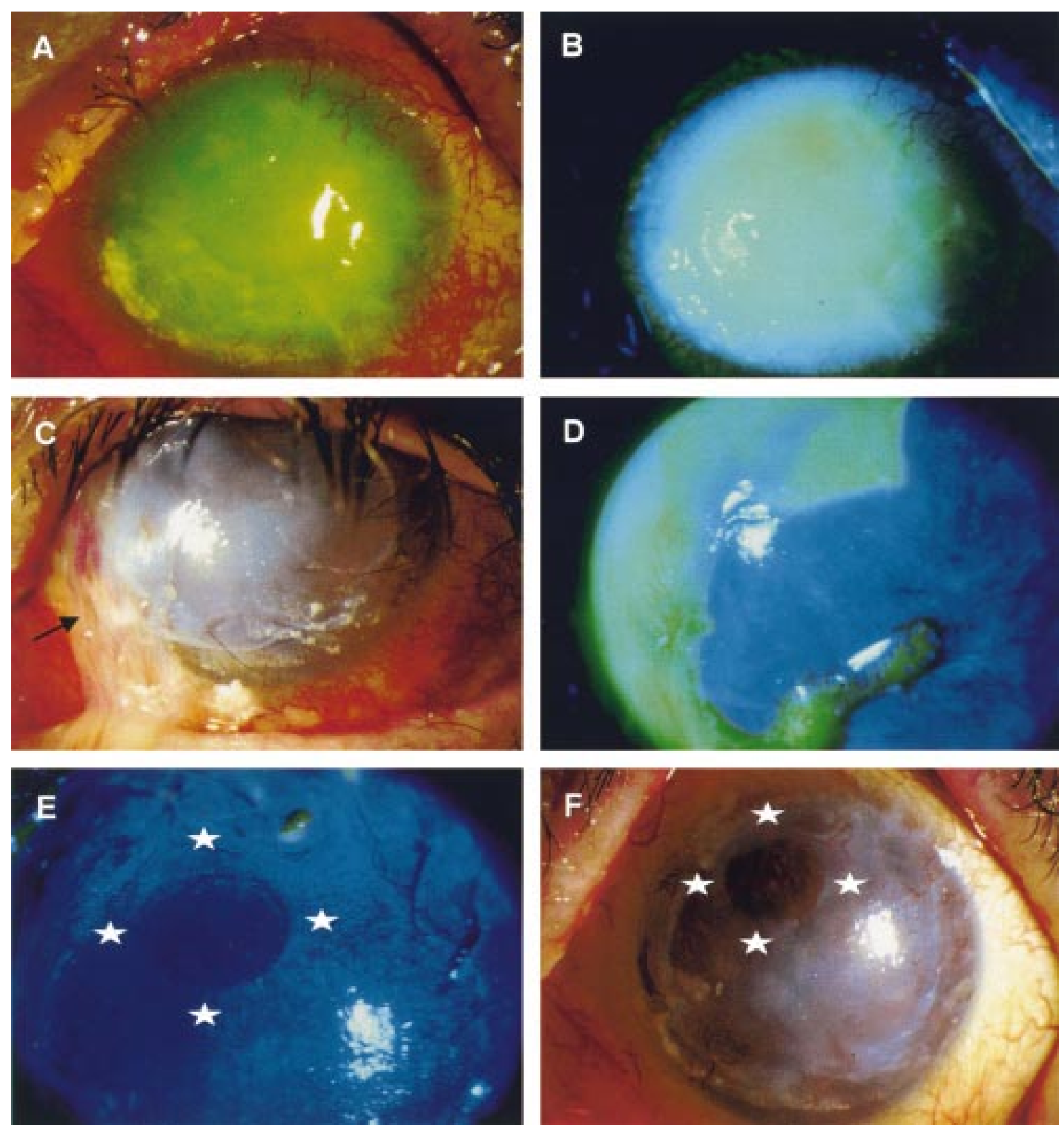

Figure 3 Case 15 had received multiple surgeries for recurrent retinal detachment in the left eye resulting in a persistent neurotrophic corneal ulcer with band keratopathy $(A$ and $B)$. Eight days after amniotic membrane transplantation (AMT), part of the membrane used as a patch started to dissolve (arrow) (C), while epithelial healing had taken place as shown by fluorescein staining (D). One month after AMT the membrane covered surface was totally healed and smooth with a small part of the membrane dissolved (indicated by asterisks) ( $E$ and $F$ ). The corneal surface continued to be stable and remained uninflamed $(F)$.

when partial tarsorrhaphy was added and healing was completed on day 74 . In the eye of case 1 , the ulcer was successfully healed by the first attempt of AMT. After healing, penetrating keratoplasty was performed and vision improved from LP to HM. Unfortunately, the corneal surface broke down with progressive ulcer leading to corneal perforation at the graft-host junction. The second attempt at AMT was performed without success and finally the eye required repeat PKP and partial tarsorrhaphy.

A remarkable reduction in ocular inflammation was accompanied by rapid epithelialisa- tion. During the follow up period of 18.8 (13.0) months, visual acuity was improved in eight eyes $(50 \%)$ with two eyes improving in visual acuity to 20/50 (case 3) (Fig 1) following repeat penetrating keratoplasty, and AMT as a patch yielding 20/80 (case 4) (Fig 2). The visual acuity did not show any change in six eyes $(37.5 \%)$, but was worsened in two eyes $(12.5 \%)$ owing to progressive glaucoma and cataract. All eyes achieved the objective of maintaining anatomical integrity. All membranes were partially (Fig 3E, F) or completely dissolved (Fig 2E, F), and the remaining stroma showed variable amounts of opacity. 


\section{Discussion}

This report shows that AMT can be considered as another effective surgery for treating severe neurotrophic corneal ulcers. The common denominator of these 16 eyes that had developed persistent or progressive corneal ulcers was the neurotrophic state caused by direct damage to the corneal sensory nerve. The nerve was affected by infection by herpes (HSV and HZO) keratitis, ischaemia due to severe diabetes mellitus, radiation, or surgical removal of acoustic neuroma. In addition, multiple anterior segment surgeries including penetrating keratoplasty could have further diminished ocular sensitivity and decreased limbal stem cell population. ${ }^{31}$ The neurotrophic state may have a direct deleterious effect on the corneal epithelium. ${ }^{32}$ Although the exact trophic substance(s) has not been identified, clinical trials using topical insulinlike growth factor type I and substance $\mathrm{P},{ }^{9}$ or nerve growth factor, ${ }^{10}$ have shown promising results for treating neurotrophic corneal ulcers.

Once corneal anaesthesia sets in and persists, other sequelae on the ocular surface can develop as a result of tear film deficiency and exposure due to interruption of two corneal nerve mediated reflex arcs - that is, aqueous tear secretion and eyelid blinking, respectively (for review see Tseng and Tsubota ${ }^{1}$ ). That was why 10 eyes $(62.5 \%)$ suffered from keratoconjunctivitis sicca and 15 eyes (93.7\%) showed decreased blinking and exposure keratitis. Such eyes frequently develop persistent corneal epithelial defects and ulceration, are unable to withstand microtrauma from trichiasis, lagophthalmos, and neuroparalysis of the seventh nerve, and are poor candidates for penetrating keratoplasty (see review by Donzis and Mondino ${ }^{2}$ ).

The severity of the neurotrophic damage on the corneal surface is illustrated in all these 16 eyes by their breakdown despite conventional tear substitutes, punctal occlusion, patching, botulinum toxin, or gold weight induced ptosis or tarsorrhaphy. During a mean follow up period of 18.8 (13.0) months, all but four AMT $(13 / 17,76.4 \%)$ ulcers healed. Epithelialisation took place in 16.6 (9.0) days in these 13 eyes. This result is consistent with our previous report in which AMT was also used to treat corneal ulcers caused by other aetiologies, ${ }^{13}$ and in agreement with a recent report by Kruse et $a l,{ }^{15}$ who successfully treated with multilayered AMT nine of 11 eyes with neurotrophic corneal ulcers. Besides the well known actions of the basement membrane in supporting epithelial adhesion, growth, and differentiation, and in preventing epithelial apoptosis, ${ }^{33}$ our recent study suggests that the basement membrane of the amniotic membrane can also prolong the lifespan of the epithelial progenitor cells. ${ }^{345}$ Such epithelial promoting actions are further augmented by the fact that the amniotic membrane can release several supportive growth factors. ${ }^{36}$

In this study, the amniotic membrane was sutured as a graft only to cover the ulcerated area. As described in our earlier report $t^{13}$ and recently by Kruse et $a l,{ }^{15}$ under this membrane we usually laid more than one layer of membrane to build up the corneal thickness in eyes with deep ulcers or descemetocele. In some eyes, we added a larger layer of membrane on top of this membrane as a temporary patch in a manner proposed by Kim et $a l .^{37}$ This membrane as a patch frequently dissolved upon epithelialisation as shown in case 15 (Fig 3C, D). The rationale of using AMT as a patch (case 4 ) was when the stromal thinning was minimal and the ulcer bed appeared to be non-necrotic. The rationale of using AMT as a patch in addition to using it as a graft (cases 8, $11,12,14$, and 15) was to prevent surface exposure and dryness and promote epithelial healing in these cases with poor blinking reflex. Constant protection and wetting of the ulcerated area by the membrane is also beneficial and AM uses as a patch may function like tarsorrhaphy to minimise exposure. When used as a patch, AM is invariably dissolved. When used as a graft, AM promotes epithelialisation over it, and is frequently preserved and may become quite transparent over time.

Also consistent with the report by Kruse et $a l,{ }^{15}$ we noted in this study that ocular surface inflammation was markedly reduced following AMT (Fig 2E, F). This finding may be explained by other recent studies showing that the stromal matrix of the amniotic membrane excludes inflammatory cells, ${ }^{38}{ }^{39}$ contains various forms of protease inhibitors, ${ }^{40}$ and suppresses transforming growth factor $\beta$ (TGF- $\beta$ ) signalling, and proliferation and myofibroblast differentiation of normal human corneal and limbal fibroblasts. ${ }^{41}$

Nevertheless, it is important to point out that persistent exposure is one limiting factor for AMT as delayed epithelialisation was noted in four eyes with very poor eyelid blink; one had Parkinson's disease following intracranial surgery (case 1), two had severe diabetes with amputation of both legs (case 7), and one suffered combined HZO and severe diabetic neuropathy (case 5). To remedy this situation, we advise early partial tarsorrhaphy. Because the neurotrophic state invariably leads to aqueous tear deficiency, we advise that punctal occlusion be performed before tarsorrhaphy. Prolonged exposure also explains why the membrane eventually dissolved partially or totally. Although recurrent breakdowns have been reported, ${ }^{15}$ for reasons still not clear some ulcers remained healed even if the membrane was completely dissolved.

Another limitation of AMT may occur in patients with limbal (stem cell) deficiency (reviewed by Tseng and Tsubota ${ }^{1}$ ). Based on the cytological criterion of conjunctivalisation, we have previously reported that limbal stem cell deficiency can develop in patients with neurotrophic keratitis. ${ }^{42}$ In these 16 eyes we noted three eyes developing partial limbal deficiency (Table 1). It is worth noting that such complications developed in two of three eyes after radiation for ocular tumours. Unlike what was reported by Fujishima $\mathrm{et} \mathrm{al}{ }^{43}$ neither of our cases reverted to normal limbal function during a prolonged follow up period and their limbal deficiency persisted. With respect to 
partial or focal limbal deficiency, Dua ${ }^{44}$ first reported the use of repetitive debridements of the conjunctivalised epithelium to restore the corneal surfaces of such patients. We recently reported that following such debridement and conjunctival resection, AMT may augment the success by promoting the regeneration and expansion of remaining limbal epithelial stem cells. ${ }^{21}$ Collectively, the advantages of these approaches $^{2144}$ are apparent because limbal stem cell transplantation is not needed. The corneal ulcers in two of the three eyes with partial limbal deficiency healed following AMT without keratolimbal allograft or debridement of conjunctivalised epithelium. Future studies are thus needed to determine if indeed AMT could facilitate the expansion of the remaining limbal epithelial stem cells in the recipient eye with partial limbal deficiency and provide more value than conjunctival debridement alone as proposed by Dua. ${ }^{44}$ When limbal deficiency becomes total and diffuse, different procedures of transplanting autologous or allogeneic limbal stem cells become necessary ${ }^{19-2145}$ (also see a classification scheme proposed by Holland et $\left.a l^{46}\right)$.

Supported in part by an unrestricted grant from Research to Prevent Blindness, Inc, New York, USA

Proprietary interest: SCGT has a financial interest in the preparation and clinical uses of amniotic membrane and Bio-Tissue.

1 Tseng SCG, Tsubota K. Important concepts for treating ocular surface and tear disorders. Am $f$ Ophthalmo ocular surface

2 Donzis PB, Mondino BJ. Management of noninfectious corneal ulcers. Surv Ophthalmol 1987;32:94-110.

3 Gould HL. Treatment of neurotrophic keratitis with scleral contact lenses. Eye, Ear, Nose and Throat Monthly 1967;46 1406-14

4 Hyndiuk RA, Kazarian EL, Schultz RO, et al. Neurotrophic corneal ulcers in diabetes mellitus. Arch Ophthalmol 1977; 95:2193-6.

5 Liesegang TJ. Corneal complications from herpes zoster ophthalmicus. Ophthalmology 1985;92:316-24

6 Reed JW, Joyner SJ, Knauer WJ. Penetrating keratoplasty for herpes zoster keratopathy. Am f Ophthalmol 1989;107:25761.

7 Phan TM, Foster CS, Boruchoff SA, et al. Topical fibronectin in the treatment of persistent corneal epithelial defects and trophic ulcers. Am f Ophthalmol 1987;104:494501 .

8 McCulley JP, Horowitz B, Husseini ZM, et al. Topical fibronectin therapy of persistent corneal epithelial defects. Fibronectin Study Group. Trans Am Ophthalmol Soc 1993; 91:367-86.

9 Brown SM, Lamberts DW, Reid TW, et al. Neurotrophic and anhidrotic keratopathy treated with substance $\mathrm{P}$ and insulinlike growth factor I. Arch Ophthalmol 1997;115:9267.

10 Lambiase A, Rama P, Bonini S, et al. Topical treatment with nerve growth factor for corneal neurotrophic ulcers. $N$ Engl f Med 1998;338:1174-80.

11 Golubovic S, Parunovic A. Cyanoacrylate glue in the treatment of corneal ulcerations. Fortschr Ophthalmol 1990;87 378-81.

12 Lugo M, Arentsen JJ. Treatment of neurotrophic ulcers with conjunctival flaps. Am f Ophthalmol 1987;103:711-2.

13 Lee S-H, Tseng SCG. Amniotic membrane transplantation for persistent epithelial defects with ulceration. $A m \mathcal{F} O p h-$ thalmol 1997;123:303-12.

14 Azuara-Blanco A, Pillai CT, Dua HS. Amniotic membrane transplantation for ocular surface reconstruction. $\mathrm{Br} \mathcal{F}$ transplantation for ocular surf

15 Kruse FE, Rohrschneider K, Völcker HE. Multilayer amniotic membrane transplantation for reconstruction of deep corneal ulcers. Ophthalmology 1999;106:1504-11.

16 Kim JC, Tseng SCG. Transplantation of preserved human amniotic membrane for surface reconstruction in severely damaged rabbit corneas. Cornea 1995;14:473-84.

17 Sorsby A, Symons HM. Amniotic membrane grafts in caustic burns of the eye. Brf Ophthalmol 1946;30:337-45.

18 Sorsby A, Haythorne J, Reed H. Further experience with amniotic membrane grafts in caustic burns of the eye. $\mathrm{Br} F$ Ophthalmol 1947;31:409-18.
19 Tsubota K, Satake Y, Ohyama M, et al. Surgical reconstruction of the ocular surface in advanced ocular cicatricial pemphigoid and Stevens-Johnson syndrome. Am f Ophthalmol 1996;122:38-52.

20 Shimazaki J, Yang H-Y, Tsubota K. Amniotic membrane transplantation for ocular surface reconstruction in patients with chemical and thermal burns. Ophthalmology 1997;104:2068-76.

21 Tseng SCG, Prabhasawat P, Barton K, et al. Amniotic membrane transplantation with or without limbal allografts for corneal surface reconstruction in patients with limbal stem cell deficiency. Arch Ophthalmol 1998;116:431-41.

22 Pires RTF, Tseng SCG, Prabhasawat P, et al. Amniotic membrane transplantation for symptomatic bullous keratopathy. Arch Ophthalmol 1999;117:1291-7.

23 Pires RTF, Chokshi A, Tseng SCG. Amniotic membrane transplantation or limbal conjunctival autograft for limbal stem cell deficiency induced by 5 - fluorouracil in glaucoma surgeries. Cornea 2000; (in press).

24 Prabhasawat P, Barton K, Burkett G, et al. Comparison of conjunctival autografts, amniotic membrane grafts and primary closure for pterygium excision. Ophthalmology 1997; 104:974-85.

25 Tseng SCG, Prabhasawat P, Lee S-H. Amniotic membrane transplantation for conjunctival surface reconstruction. Am 7 Ophthalmol 1997;124:765-74.

26 Shimazaki J, Shinozaki N, Tsubota K. Transplantation of amniotic membrane and limbal autograft for patients with recurrent pterygium associated with symblepharon. $\mathrm{Br} F$ Ophthalmol 1998;82:235-40.

27 Kim JC, Lee D, Shyn KH. In: Lass JH, ed. Advances in corneal research. New York: Plenum Press, 1997:117-34.

28 Duchesne B, Mans B, Lavalleye B, et al. Utilisation de la membrane amniotique humaine cryo-preservee pour la reconstruction de la surface oculaire. Bull Soc Belge Ophtalmol 1998;268:73-7.

29 Fujishima H, Shimazaki J, Shinozaki N, et al. Trabeculectomy with the use of amniotic membrane for uncontrolled glaucoma. Ophthalmic Surg Lasers 1998;29:428-31.

30 Pires RTF, Pires J-L, Tseng SCG. Transplante de membrana amniótica para reconstrução da superfície corneana e conjuntival. Arq Bras Oftalm 1999;62:340-50.

31 Schwartz GS, Holland EJ. Iatrogenic limbal stem cell deficiency. Cornea 1998;7:31-7.

32 Beuerman RW, Schimmelpfennig B. Sensory denervation of the rabbit cornea affects epithelial properties. Exp Neurol 1980;69:196-201.

33 Boudreau N, Werb Z, Bissell MJ. Suppression of apoptosis by basement membrane requires three-dimensional tissue organization and withdrawal from the cell cycle. Proc Natl Acad Sci USA 1996;93:3500-13.

34 Meller D, Tseng SCG. Conjunctival epithelial cell differentiation on amniotic membrane. Invest Ophthalmol Vis Sci 1999;40:878-86.

35 Meller D, Pires RTF, Tseng SCG. Ex vivo preservation and expansion of human limbal epithelial progenitor cells by amniotic membrane. Invest Ophthalmol Vis Sci 1999;40: S329.

36 Sato H, Shimazaki J, Shinozaki K, et al. Role of growth factors for ocular surface reconstruction after amniotic membrane transplantation. Invest Ophthalmol Vis Sci 1998;39: S428.

37 Kim JS, Park SW, Kim JH, et al. Temporary amniotic membrane graft promotes healing and inhibits protease activity in corneal wound induced by alkali burns in rabbits. Invest Ophthalmol Vis Sci 1998;39:S90.

38 Wang MX, Gray T, Parks WC, et al. Corneal haze and apoptosis is reduced by amniotic membrane matrix in excimer laser photoablation in rabbits. $\mathcal{F}$ Cataract Refract Surg 2000; (in press).

39 Park WC, Tseng SCG. Temperature cooling reduces keratocyte death in excimer laser ablated corneal and skin wounds. Invest Ophthalmol Vis Sci 1998;39:S449.

$40 \mathrm{Na}$ BK, Hwang JH, Shin EJ, et al. Analysis of human amniotic membrane components as proteinase inhibitors for development of therapeutic agent of recalcitrant keratitis. Invest Ophthalmol Vis Sci 1998;39:S90.

41 Tseng SCG, Li D-Q, Ma X. Suppression of TGF- $\beta 1, \beta 2$, $\beta 3$, and TGF- $\beta$ receptor II expression and myofibroblast differentiation in human corneal and limbal fibroblasts by amniotic membrane matrix. F Cell Physiol 1999;179:32535 .

42 Puangsricharern V, Tseng SCG. Cytologic evidence of corneal diseases with limbal stem cell deficiency. Ophthalmology 1995;102:1476-85.

43 Fujishima H, Shimazaki J, Tsubota K. Temporary corneal stem cell dysfunction after radiation therapy. $\mathrm{Br} \mathcal{F}$ Ophthalmol 1996;80:911-4.

44 Dua HS. The conjunctiva in corneal epithelial wound healing. Br f Ophthalmol 1998;82:1411.

45 Tsubota K, Satake Y, Kaido M, et al. Treatment of severe ocular surface disorders with corneal epithelial stem-cell transplantation. N Engl F Med 1999;340:1697-703.

46 Holland EJ, Schwartz GS. The evolution of epithelial transplantation for severe ocular surface disease and a proposed classification system. Cornea 1996;15:549-56. 